\title{
Authenticity Promotes Student Engagement and Learning in a Stand-Alone Technical Communications Course
}

Dr. Shannon Ciston, University of California, Berkeley

Dr. Shannon Ciston is a lecturer in the Chemical Engineering Department at the University of California, Berkeley, where she teaches courses in technical communications, first-year design, and pedagogy. Dr. Ciston holds degrees in Chemical Engineering from Northwestern University and Illinois Institute of Technology. Her research interests include aspects of engineering student experience, identity, and motivation, especially among first-year students and non-traditional adult students.

Mr. Sean Poust, University of California-Berkeley 


\section{Authenticity Promotes Student Engagement and Learning in a Stand-Alone Technical Communications Course}

Technical Communications for Chemical Engineers has recently been reintroduced to the chemical engineering undergraduate curriculum at the University of California, Berkeley. The goal of the course is for students to gain skills in written, oral, and interpersonal communications that will help them excel in their careers and in senior-level capstone design and laboratory courses. The course runs as a one-semester, stand-alone course (not coupled to a complementary technical or laboratory course) with assignments ranging from laboratory reports, design reports, resumes, cover letters, interviews, technical presentations, and project proposals to communication with lay audiences. This paper takes a case study approach to examine the evolution of the laboratory report assignment over the course of three semesters. We found that incorporating additional authenticity into laboratory report writing assignment motivated student engagement and learning. Midterm and final course evaluations are used as data to reflect on the effectiveness of three iterations of the assignment:

- Fall 2011: Common Topic; Data from physical experiment conducted by an unknown student - Spring 2012: Individual Topic; Data from physical experiment conducted by the student in a previous course

- Fall 2012: Common Topic; Data from simulation conducted by the student in this course

Instructor observations and student feedback demonstrate the importance of engaging the student in all stages of the experiment, including collection of data. The utilization of a simulation allowed for the incorporation of authenticity into the course, while respecting the time and other constraints of a stand-alone technical communications course. This approach is being extended to other assignments in the course, with more authentic assignments being implemented for the design and proposal topics. This will complement the assignments for resumes, cover letters, and lay audience presentations that already provide a "real-world" application of the students' work. This methodology can be applied to other stand-alone technical communications courses in engineering, to provide meaningful context and motivation.

\section{Communications Training for Engineers}

The ability to communicate effectively is a critical skill for engineers. Strong communication skills are necessary for high-functioning engineering teams, successful projects, promotive workplace interactions, and career advancement. Engineering practitioners, educators, and students recognize communication as one of the key skills for engineering work, with over $60 \%$ of engineering seniors surveyed rating communication among the top five most important engineering skills, in a recent study reported in Enabling Engineering Student Success. ${ }^{1}$ 
Communication skills for engineers have been a focus of many prior papers and reports that focus on communication in the engineering workplace, ${ }^{2}$ development of written communication skills, ${ }^{3}$ oral communication skills, ${ }^{4}$ and international and global communications. ${ }^{5}$ The ABET Engineering Accreditation Commission has established communication skills as a Student Outcome for all accredited engineering programs in Outcome g: an ability to communicate effectively. ${ }^{6}$

This need to educate engineering students in the written, oral, and interpersonal communication skills necessary for career success is manifest differently across many engineering departments. While some departments provide communication training distributed across many courses (such as writing or speaking assignments in core technical courses), others have developed specific Technical Communications courses targeted for engineers. The targeted courses are sometimes coupled closely with a technical course, acting as a co-requisite for a required technical course or capstone design course. In this "coupled" style of course, the content of the technical course provides a context for communication skills development, such as writing a report and preparing a presentation for a design project developed in the capstone course. There may be a separate communications-focused faculty member to complement the technical instructor, or the technical instructor may perform both functions. A second type of technical communications course in engineering curricula is the "stand-alone" course in which communication skills are developed without any specific coupling to a second required course. A recent article in the ASEE Prism magazine highlighted some different approaches for teaching presentation skills specifically, ${ }^{7}$ featuring the technical communications or professional development courses for engineering students at NCSU, Texas Tech, and Vanderbilt, and the Bucknell bioengineering approach of distributing communications assignments across many engineering courses in the curriculum.

Stand-alone courses may have several benefits: increased flexibility to cover communication types that are career-relevant but not natural choices for the technical content of a particular course, opportunities to combine instruction for students of multiple majors or multiple levels in the curriculum and ease of addition to existing engineering curricula. A major challenge for the instructor of a stand-alone technical communications, course, however, is to create meaningful and authentic communications assignments without the context of the shared technical course. This paper focuses on a stand-alone technical communications course for chemical engineering majors, specifically focusing on the development of authentic, quality assignments to develop communications skills.

\section{$\underline{\text { Authenticity as a Value in Learning and Education }}$}


Authenticity in student courses is a long-held value in education. Some of the earliest models for higher education were based on an apprenticeship and job-training approach in which pupils practiced the skills and techniques of their trade under the supervision of a master. Students today continue to desire educational experiences that provide experience with "real-world" problems, and are relevant to their future careers. Modern systems of higher learning typically combine experiential or applied learning experiences with more general or abstract learning environments intended to develop transferable critical thinking skills.

Jon Mueller of North Central College in Illinois is a proponent of "Authentic Assessment." He defines authentic assessment as "a form of assessment in which students are asked to perform real-world tasks that demonstrate meaningful application of essential knowledge and skills." Authentic assessment is focused on performing a task with a real-life basis, with student application of direct evidence. ${ }^{8}$

\section{Authenticity in Engineering Education}

Authenticity has also been discussed within the context of engineering education. As engineering educators, we may take an authentic assessment approach through a variety of routes, such as industry-sponsored design projects, problem-based learning, academic service learning. In particular, authenticity is a theme frequently discussed within the context of design experiences and online learning.

Dutson and coauthors' review of project-oriented capstone design courses brings out authenticity as an important factor in teaching design, calling on Harrisberger's perspective on authentic involvement: "The authentic involvement activities expose the student to real situations with totally open-ended projects, although the faculty may influence the selection of the situations and set performance criteria to assure that positive learning objectives are met." $" 9,10$

In the online teaching and learning environment, authenticity is a special concern because of the increased degree of separation between the student and the instructional classroom. Reeves, Herrington, and Oliver suggest ten characteristics of authentic learning for use in the design of online learning experiences. Authentic activities should: have real-world relevance, be illdefined to require students to define tasks, comprise complex tasks to be investigated over a period of time, provide an opportunity to examine tasks from different perspectives, provide opportunity to collaborate, provide opportunity to reflect, be integrated across learning domains, integrate seamlessly with assessment, create valuable products, and allow a diversity of outcomes or solutions. ${ }^{11}$

To engage engineering students in the process of learning communications skills, it is crucial to make their learning experience authentic as well. Some examples of ways to make these 
assignments realistic are to engage students with real engineering practitioners or clients. For example, Dean Fontenot at Texas Tech has structured a Professional Communications for Engineers course around a service-learning experience. ${ }^{7}$ Engineering alumni can be invited to participate in the class for mock interviews, discussion panels, or judges rating presentations or reports.

\section{Our Course: Technical Communications for Chemical Engineers}

Technical Communications for Chemical Engineers at the University of California, Berkeley, is a junior-level course designed for the development of written, oral, and interpersonal communication skills. The course ran continuously as required course for over 20 years until Fall 2007. The course was recently redeveloped and reintroduced in Fall 2011, after a four-year hiatus, and was phased-in as an optional elective course in 2011-2012 and 2012-2013 academic years. It is a required course for the class of 2015. The course runs multiple sections each semester of up to 30 students each section, serving approximately 100 students each year. The total number of sections is planned to increase in response to a growing chemical engineering undergraduate body and the required status of the course. We anticipate running five sections serving about 150 students during the 2013-2014 academic year.

Technical Communications for Chemical Engineers is a three-credit, one-semester course that meets twice a week for 80 minutes each meeting. During the first four semesters of implementation, one faculty instructor has taught both sections each semester, with one graduate teaching assistant per semester supporting both sections of the course. The class meets in classrooms equipped with a chalkboard plus a media station for projecting presentations files and videos. The course is supported with an online course management system for file and resource sharing. ABET student outcomes $f$ (an understanding of professional and ethical responsibility) and $g$ (an ability to communicate effectively) are supported by this course. The full set of course outcomes are:

At the conclusion of the course, students will be able to:

1. Identify the purpose, desired outcomes, and audience needs for various types of technical communication.

2. Write clearly, directly, and concisely in technical documents.

3. Identify and apply standard formats for common technical documents including resumes, cover letters, statements of purpose, project proposals, design reports, laboratory reports, and journal articles.

4. Use visuals including charts, diagrams, graphs, presentations slides, and tables to communicate ideas.

5. Speak clearly and effectively in situations with and without advanced preparation. 
6. Adapt communication approaches for technical, non-technical, and managerial audiences.

7. Apply modern communication technologies.

8. Recognize the ethical responsibility of engineers, and articulate morally justified solutions to ethical problems.

Technical Communications is a workshop-style course featuring multiple-draft assignments, extensive feedback from instructors and peers, active learning exercises in class, and a combination of group and individual assignments. The course develops skills in audience analysis; public speaking; document formatting; construction of direct, clear, concise arguments; organizing ideas; listening; and using graphics and design to communicate information. Typical assignments include a project proposal, a laboratory report, a design report, two or more formal oral presentations, an impromptu ethics case study speech, resumes and cover letters, and an assignment to communicate technical information to a non-engineering audience via a blog or educational video.

Including meaningful, authentic assignments has been a goal of the course design for Technical Communications for Chemical Engineers at the University of California, Berkeley. For example, students are encouraged to create resumes and cover letters tailored for real internship or entry-level job applications. Program alumni and other practicing engineers and scientists have been invited to the course to interact with students in panel discussions. Assignments to practice technical communication with non-engineers have included collaborative partnerships with a middle-school classroom and science bloggers.

Extending the authentic communication experience to formal report writing assignments in a stand-alone course has been challenging. For example, the project proposal writing assignment evolved from a proposal assignment with no application beyond the course to a more authentic assignment. In the Fall 2012 course offering, a project proposal assignment was taken as the Environmental Protection Agency's P3 (People, Prosperity, Planet) Awards program for students, so that student teams could have the option of submitting their proposal to a real competition. Laboratory report assignments have varied each semester in an attempt to develop an assignment that is authentic and gives students an opportunity to develop their formal report writing skills, while also respecting time constraints for the students, the course format and the instructor/grader team.

\section{Case Study: Laboratory Report Assignment}

Assignment Objectives: The laboratory report assignment is aimed to help students improve their laboratory report writing skills. Specifically, they should be able to: 
- Organize information clearly into the four major sections: Introduction, Methods, Results, Discussion.

- Apply standard formatting for title page, works cited, figures, equations, and headings.

- Compose prose that is clear, concise, and direct, with appropriate tone, word choice, and level of technical detail for the given audience.

- Produce graphics that are clear, integrated with the text narrative, and use appropriate units, labels, headings, symbols, and color.

\section{Assignment Details:}

Fall 2011 Students were assigned to write a laboratory report, given a laboratory manual and a set of real raw data collected by a freshman engineering student from the Chemistry with Biological Applications for Engineers course at the University of New Haven. These were from a kinetics experiment, for calculation of the reaction rate equation of the decomposition of hydrogen peroxide using an iodide catalyst. Students were required to complete the calculations using the raw data, produce charts and graphs, and write the full written report. The raw data was not manipulated before providing it to the students, and so it contained one measurement that was not consistent with the others. The instructor considered this to be a reasonable constraint because student laboratory data may often have some degree of error. All students worked with the same data and report assignment.

Spring 2012 This assignment was focused on rewriting and revision. Students were required to choose one of the reports they had written for a previous or current laboratory course (such as a chemistry or engineering laboratory course) and to revise it to create "the best report they have ever written." There was a high degree of variability among the students' selections of laboratory reports for revision. Some were short-form reports of only 2-3 pages, while others were long-form formal reports of experiments with multiple parts including simulation and experiments, stretching to 15-20 pages.

Fall 2012 This laboratory assignment was based on an online computer simulation of gas absorption with chemical reaction, provided by the Wolfram Demonstrations Project. ${ }^{12}$ Students were required to collect data from the simulation, varying the liquid phase concentration of both reactants and the reaction rate constant, recording the value of the flux of the reactant being absorbed in the system. They were required to plot and interpret this data with the formal laboratory report format. All students worked with the same simulation, but collected data individually.

\section{Evaluation of Midterm and Final Course Feedback:}


During each offering of the course, students were solicited for course feedback via midterm surveys and final surveys. Each of these surveys included open-ended questions about aspects of the course that were specifically effective or ineffective, and prompted students to make suggestions for course improvement. None of these surveys specifically asked students to rate or comment on the laboratory report assignments.

The open-ended responses for each survey were analyzed for any mention of the laboratory report assignment. All comments referring to the laboratory report assignment were transcribed and coded with a value of +1 for positive comments that indicated the assignment was effective (example: "The lab report especially refined my skills of writing a neatly formatted report."), a value of -1 for negative comments that indicated the assignment was ineffective (example: "least satisfied with the lab report writing task"), or a value of 0 for those comments that were neutral or indicated that some adjustment should be made to improve the assignment design (example: "I would have liked lab/design reports earlier in the semester...”).

The comments were reviewed for recurring themes and ideas within one semester and across semesters. A numerical score was also calculated for each semester, by summing the values for each comment.

In Fall 2011, there were a total of 12 comments addressing the laboratory report assignment; seven were negative and five were neutral, with an overall score of -7 . Themes common in the feedback from the Fall 2011 semester include the idea that the assignment was too long or too much work, and the need for improved or processed raw data. These comments reflect the frustration many students expressed verbally in having to interpret problematic data collected by a real student (not themselves) in the lab. Notably, one comment uses the phrase "fake lab reports", demonstrating that the assignment was not as authentic as intended. Many of the students balked at the large workload of the assignment; it was the first long document assigned for the course. (A total of 19 students completed midterm feedback forms administered in class, and 20 students completed final feedback forms administered in class.)

In Spring 2012, there were a total of four comments on the lab report assignment, all of them neutral, with an overall score of 0 . All four comments for Spring 2012 reflected a desire to have the laboratory report assignment earlier in the semester. Several students were taking the laboratory course concurrently with the technical communications course, and they wished to have training earlier. In this offering of the assignment, students revised and restructured reports they had written for previous lab courses--a much lower workload compared to the previous semester. However, a wide diversity in student writing topics increased the effective grading load for the instructional team. (A total of 54 students completed midterm feedback forms administered in class, and 53 students completed midterm feedback forms administered in class.) 
In Fall 2012, there were a total of eight comments about the laboratory report; five were negative, one was neutral, and two were positive, with an overall score of -3 . Students were split in this semester on the effectiveness of the laboratory report assignment. Two comments indicate that the assignment was helpful for improving their writing skills, but several indicated that they did not learn much considering the amount of work they put into the assignment. Notably, one student commented that the lab reports were "a bit awkward because we weren't doing them 'for real'." (A total of 16 students completed midterm feedback forms administered online; 48 students completed final course feedback administered in class)

Evaluating the student comments as a whole, it is encouraging that the most recent iteration of the laboratory report produced some positive student responses. We believe this reflects an improved balance in authenticity (collecting and interpreting one's own data) and workload (gathering and plotting simulation data takes approximately one hour), and reflects the need for focused formal report writing instruction for engineering students. Nevertheless, at least one student perceived this simulation experiment as being unauthentic, and while the student workload was reduced in Fall 2012 compared to Fall 2011, some students in Fall 2012 still felt that they did not learn new skills equal to the level of workload.

The task of revision of a previous laboratory report, assigned in Spring 2012 generated no positive or negative responses; it was not a significant workload for the students, but perhaps it did not engage students in learning the lab report writing skills as effectively as the Fall 2012 assignment. The task of revision can still provide an opportunity to improve student skills in organization and clear, direct writing.

\section{Evaluation of Student Performance}

Student performance on the laboratory report assignment during each semester also has potential to reveal insights about the value of each assignment type. Two types of information are considered here: student assignment scores and general trends for common types of errors and problems in each semester.

No meaningful differences were observed when comparing assignment scores from the three different semesters. Results are summarized in Figure 1 below. Students receive grades on an intermediate draft and final draft of each assignment. See Appendix A for the laboratory report scoring rubric for more details. Students receive extensive instructor feedback on the intermediate draft, and the final draft score reflects their ability to integrate and apply new insights and targeted instruction to create a final product. Throughout the course, students generally exhibit a high level of integration of the targeted feedback for improvement, resulting in very high final draft scores for most students. 


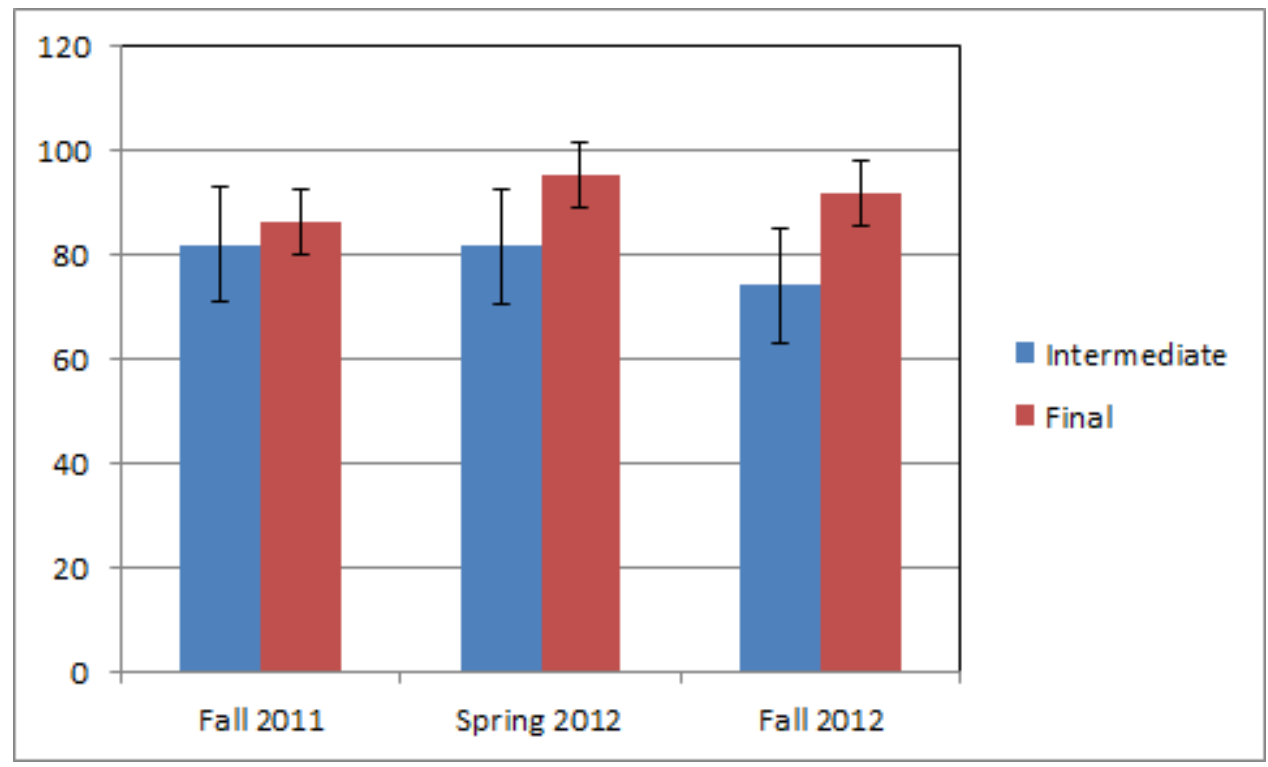

Figure 1. Average scores on laboratory report assignment are similar during each semester. Error bars represent the average standard deviation for intermediate and final drafts across three years.

While we did not observe differences in the numerical scores, we did observe differences in the typical problems, issues, and areas for revision during each semester. The following describes the typical problems the instructors observed in each set of assignments. In each case, the typical issues observed in the preceding semester became a point of in-class emphasis in the following semester. Some issues or problems seem to be specific to the nature of the assignment definition.

Fall 2011: Students presented a wide variety of problems with basic laboratory report-writing skills, especially including:

Abstracts including only methods and results, missing introductory and discussion components Problematic or missing numbering for figures and charts

Absent or scant narrative with charts and figures in results section

Use of present tense to describe methods

Missing subscripts for chemical formulas

Imprecise word choice (e.g. using "pipe" or "hose" in place of "tubing")

Spring 2012: Students responded well to exercises to practice writing effective abstracts.

Problems remained or emerged in the following areas:

Incomplete introductions, without a full purpose statement, and previous work background Misplacement of information, especially material placement in introduction versus methods Struggles to organize information for complex multi-part laboratory assignments 
Fall 2012: Students experienced some confusion about details of writing about a simulation experiment.

Problems with fully describing the methods

Problems with interpretation of results

\section{Discussion and Recommendations}

Many engineering curricula under emphasize development of communication skills. However, as stated in ABET Outcome g, developing communications skills in today's engineering students is crucial. To fully engage engineering students in the communication courses available, we recommend that integrated and stand-alone technical communications courses for engineers engage students in authentic communication experiences whenever possible. Assignments that give engineering students an opportunity to interact with real clients or partners are ideal, but it may be necessary to supplement these experiential learning activities with classroom assignments that integrate some components of authenticity.

We can summarize the results of our analysis and experience with offering these three iterations of a laboratory report assignment. During the first semester, all student laboratory report feedback was negative, but there was a shift to more balanced feedback in the third semester. Students were more engaged and enjoyed the more authentic simulation-based assignment. There were many fewer typical problems exhibited in student work during the third semester, providing support for improved student learning. Instructors encountered strongly negative student attitudes in the classroom regarding the first laboratory report assignment, chiefly centered on the quality of the data and the process for data analysis required for the assignment. During the second semester, instructors found students typically disengaged with the assignment, focused only on the mechanics of revision and rewriting. Based on instructor's observations, the third semester's simulation assignment provided the most balanced learning opportunity for students who more clearly understood the experiment and engaged positively in new analysis, synthesis, and report writing. We find the simulation experiment to be the most authentic and effective mode for this assignment. A similar assignment has been successfully implemented in the Spring 2013 semester, applying a second simulation. ${ }^{13}$

In comparing three iterations of a laboratory report writing assignment in a stand-alone technical communications course, we recommend the use of simulations as a basis for writing a laboratory report. The simulation approach taken in the Fall 2012 semester gave the students an authentic data analysis experience, since they collected their own data and interpreted it as part of their laboratory report writing assignment. Based on student feedback, the collection of one's own data is essential for an authentic laboratory report writing experience. Students also met learning objectives more consistently for his version of the assignment. From the instructor's perspective, 
the majority of students were positively engaged with this assignment, as evidenced by student questions about organization, data interpretation, and analysis. Using an online simulation provides an outlet for collection of data within constraints of a stand-alone technical writing course: limited time and laboratory equipment resources; and is an effective way to engage students in laboratory report writing.

\section{Works Cited}

1 Atman, Cynthia J., Sheri D. Sheppard, Jennifer Turns, Robin S. Adams, Lorraine N. Fleming, Reed Stevens, Ruth A. Streveler, Karl A. Smith, Ronald L. Miller, Larry J. Leifer, Ken Yasuhara, \& Dennis Lund. (2010). Enabling engineering student success: The final report for the center for the advancement of engineering education. San Rafael, CA: Morgan \& Claypool

Publishers. (http://www.engr.washington.edu/caee/CAEE\%20final\%20report\%2020101102.pdf)

2 Donnell, Aller, Alley, Kedrowicz. (2011). Why Industry Says That Engineering Graduates Have Poor Communication Skills: What the Literature Says. Proceedings of the American Society for Engineering Education.

3 Durfee, Adams, Appelsies, Flash. (2011). A Writing program for Mechanical Engineering. Proceedings of the American Society for Engineering Education.

$4 \quad$ Utschig, Norback, Bryan. (2012). Workforce Communication Instruction: Preliminary Inter-rater Reliability Data for an Executive Based Oral Communication Rubric. Proceedings of the American Society for Engineering Education.

5 Reimer, M. J. (2007). "English and Communication Skills for the Global Engineer" Global J. of Engng. Educ., Vol.6, No.1 (http://www.wiete.com.au/journals/GJEE/Publish/vol6no1/Riemer.pdf)

6 ABET (2012). Criteria for Accrediting Engineering programs, 2013-2014.

(http://www.abet.org/DisplayTemplates/DocsHandbook.aspx?id=3149)

7 Grose, Thomas. (2012). Wow the Audience. Prism. December 2012. American Society for Engineering Education.

8 Mueller. (2012.) Authentic Assessment Toolbox: What is Authentic Assessment? (http://jfmueller.faculty.noctrl.edu/toolbox/whatisit.htm)

9 Dutson, Todd, Magleby, Sorensen. (1997). A Review of Literature on Teaching Engineering Design Through Project Oriented Capstone Courses. Journal of Engineering Education.

10 Harrisberger, L., R. Heydinger, J. Seeley, and M. Talburtt, Experiential Learning in Engineering Education, American Society for Engineering Education, 1976. 
11 Reeves, T.C., Herrington, J. and Oliver, R. (2002) Authentic activities and online learning. In: HERDSA 2002 Quality Conversations, 7 - 10 July 2002, Perth, Western Australia.

12 Binous, Houssam. Wolfram Demonstrations Project: Gas Absorption with Chemical Reactions. (http://demonstrations.wolfram.com/GasAbsorptionWithChemicalReactions/)

13 Binous, Houssam. Wolfram Demonstrations Project: Packed Bed Reactor Design for a Gas Phase Catalytic Reaction. (http://demonstrations.wolfram.com/PackedBedReactorDesignForAGasPhaseCatalyticReaction/) 


\section{Appendix A: Laboratory Report Rubric}

\begin{tabular}{|c|c|c|c|}
\hline \multicolumn{4}{|c|}{ Laboratory Report Rubric } \\
\hline Title Page & 3 & 2 & 1 \\
\hline & Descriptive title, author(s), date & One item absent or unclear & $\begin{array}{c}\text { Multiple items absent or } \\
\text { unclear }\end{array}$ \\
\hline \multirow[t]{2}{*}{ Abstract } & 3 & 2 & 1 \\
\hline & $\begin{array}{c}\text { Concisely summarizes intro, } \\
\text { methods, results, and conclusions. } \\
\text { Includes quantitative results. }<400 \\
\text { words }\end{array}$ & $\begin{array}{c}\text { Missing quantitative report of } \\
\text { major findings, } \\
\text { OR too long }\end{array}$ & $\begin{array}{l}\text { Missing one or more } \\
\text { section (IMRD) }\end{array}$ \\
\hline \multirow[t]{2}{*}{ Table of Contents } & 2 & 1 & \\
\hline & $\begin{array}{l}\text { Lists sections ( } \& \text { subsections) and } \\
\text { page numbers. Clearly formatted }\end{array}$ & $\begin{array}{c}\text { Lack of section/subsections, lack } \\
\text { of page numbers, or poor } \\
\text { formatting }\end{array}$ & -- \\
\hline \multirow[t]{2}{*}{ Introduction } & $8-10$ & $5-7$ & $0-4$ \\
\hline & \begin{tabular}{|} 
Shows the necessity of the \\
experiment by discussing relevant \\
theory and previous work. Explicitly \\
states the purpose or hypothesis. \\
Orients the reader to the \\
experiment.
\end{tabular} & $\begin{array}{l}\text { Describes the purpose or } \\
\text { hypothesis, but does not } \\
\text { provide sufficient detail in } \\
\text { discussion of previous work to } \\
\text { show the necessity of the } \\
\text { experiment. }\end{array}$ & $\begin{array}{c}\text { Does not clearly and } \\
\text { explicitly state the full } \\
\text { purposse or hypothesis. } \\
\text { Does not provide context } \\
\text { for the experiment. }\end{array}$ \\
\hline \multirow[t]{2}{*}{ Methods } & $8-10$ & $5-7$ & $0-4$ \\
\hline & $\begin{array}{c}\text { Describes how the purpose or } \\
\text { hypothesis was explored, with } \\
\text { sufficient detail that the method } \\
\text { may be reproduced by an } \\
\text { independent investigator. Stated in } \\
\text { clear paragraph form, with use of } \\
\text { appropriate units and equipment } \\
\text { names. }\end{array}$ & $\begin{array}{l}\text { List form rather than paragraph } \\
\text { form, OR minor errors in units, } \\
\text { equipment names }\end{array}$ & $\begin{array}{l}\text { Details are missing such } \\
\text { that the experiment } \\
\text { could not be performed } \\
\text { by an independent } \\
\text { investigator. }\end{array}$ \\
\hline \multirow[t]{2}{*}{ Results } & $8-10$ & $5-7$ & $0-4$ \\
\hline & $\begin{array}{c}\text { Describes results with clear, explicit } \\
\text { narrative, accompanying appropriate } \\
\text { figures, tables, or graphs. Proper use } \\
\text { of chart labels, axes, units. }\end{array}$ & $\begin{array}{l}\text { Narrative is vague or abstract. } \\
\text { Misses opportunities for } \\
\text { presenting data in graphical } \\
\text { form. Minor errors in labels, } \\
\text { axes, units. }\end{array}$ & $\begin{array}{l}\text { Data presented in charts } \\
\text { without narrative, or vice } \\
\text { versa. Major errors in } \\
\text { labels, axes, units. }\end{array}$ \\
\hline \multirow[t]{2}{*}{ Discussion } & $8-10$ & $5-7$ & $0-4$ \\
\hline & $\begin{array}{l}\text { Interpretation of what the results } \\
\text { mean. Clear statement of how } \\
\text { results relate to the purpose. Direct } \\
\text { reference to data and results. } \\
\text { Scientific opinion of why you found } \\
\text { these results. }\end{array}$ & $\begin{array}{l}\text { Missing direct reference to data } \\
\text { and results. Missing } \\
\text { opportunities for interpretation } \\
\text { of results }\end{array}$ & $\begin{array}{l}\text { No statement of how } \\
\text { results relate to the } \\
\text { purpose or hypothesis, or } \\
\text { missing multiple } \\
\text { elements. }\end{array}$ \\
\hline \multirow[t]{2}{*}{ Works Cited } & 5 & $3-4$ & $0-2$ \\
\hline & $\begin{array}{l}\text { Follows ACS Style Guide format with } \\
\text { in-line citations and endnotes }\end{array}$ & One or two formatting errors & $\begin{array}{l}\text { Many formatting errors } \\
\text { OR Missing references }\end{array}$ \\
\hline \multirow[t]{2}{*}{ Spelling/Grammar, Format } & \begin{tabular}{|c|}
5 \\
\end{tabular} & $3-4$ & $0-2$ \\
\hline & $\begin{array}{l}\text { Meticulously edited. Clear format } \\
\text { with subheadings }\end{array}$ & A few minor errors & $\begin{array}{l}\text { Many errors which } \\
\text { distract reader }\end{array}$ \\
\hline \multirow[t]{2}{*}{ Clarity and Precision } & 5 & $3-4$ & $0-2$ \\
\hline & $\begin{array}{l}\text { Clear, direct, concise, and precise } \\
\text { sentences; focused paragraphs } \\
\text { throughout }\end{array}$ & Minor errors & Major errors \\
\hline
\end{tabular}

